\title{
IMPACT OF COVID-19 ON MULTIPLE BODY ORGAN FAILURE: A REVIEW
}

\author{
AYA YASEEN MAHMOOD ALABDALI ${ }^{1}$, SASIKALA CHINNAPPAN ${ }^{2 *}$, BASMA M. ABD RAZIK ${ }^{3}$, MOGANA R. ${ }^{4}$, SHAIK \\ IBRAHIM KHALIVULLA ${ }^{5}$, RAHMAN H. ${ }^{6}$
}

1,2,4,5,6Department of Pharmaceutical Biology, Faculty of Pharmaceutical Sciences, UCSI University Kuala Lumpur (South Wing), No. 1, Jalan Menara Gading, UCSI Heights 56000 Cheras, Kuala Lumpur, Malaysia, ${ }^{1}$ The University of Mashreq, College of Pharmacy, Baghdad, Iraq, ${ }^{3}$ Department of Pharmaceutical Chemistry, College of Pharmacy, Mustansiriyah University, 10001, Baghdad, Iraq Email: ayaalabdaly@hotmail.com

Received: 25 Mar 2021, Revised and Accepted: 19 Jun 2021

\section{ABSTRACT}

COVID-19 is a highly contagious disease caused by Severe Acute Respiratory Syndrome CoronaVirus-2 (SARS-CoV-2); which is a novel singlestranded positive RNA infection which consist of cytokines that activate the pathogenic systems that cause high respiratory pain condition, and adversely affect on multiple body organ in humans as per their immunity standards to fight against the virus. SARS-CoV-2 enters the host cell through Angiotensin-Converting Enzyme 2 (ACE 2). ACE 2 is a sub-part of the Renin-Aldosterone Angiotensin System (RAAS), intelligently communicated in the body's kidney, heart, lungs, and malignant tissues. The malfunctioning of RAAS in the body leads to hypertension, cardiovascular sicknesses, endocrine system and negatively affects a brain-body communication channel. Treatments on the RAAS structure, 'thiazolidinedione's and smoking, toxemia, kidney, lungs disorder due to the SARS-CoV-2 attack on the host cell and notice the behavioral changes of body organs the arrival of cytokines that causes multi-organ damage. This paper involves the study of the effects of coronavirus disease on multiple body-organ injuries.

Keywords: Corona virus disease (COVID-19), Organ failure, SAR-CoV-2, Cardiovascular system, Kidney, Lungs

(C) 2021 The Authors. Published by Innovare Academic Sciences Pvt Ltd. This is an open access article under the CC BY license (https://creativecommons.org/licenses/by/4.0/) DOI: https://dx.doi.org/10.22159/ijap.2021v13i5.42653. Journal homepage: https://innovareacademics.in/journals/index.php/ijap

\section{INTRODUCTION}

A novel 'coronavirus disease-19 (COVID-19)'" was unknown until December '2019 outbreak in Wuhan, China, and it was announced as a pandemic by WHO on $11^{\text {th }}$ march 2020 [1]. The novel Coronaviruses are a huge family group of infections that accuse serious body illness, leading to death, an electron microscopic image of a thin section of SARS-CoV within the cytoplasm of an infected cell, the spherical particles and cross-sections through the viral nucleocapsid [2]. The size of coronavirus is about 80-160 $\mathrm{nm}$ with 26-34 kbs single-stranded positive RNA genetic material, and also five proteins viz., spike (S), nucleocapsid (N), envelope (E), membrane (M), hemagglutinin esterase (HE) as showed in fig. 2, N shell protein enclose the positive sense single-strand RNA genome, $\mathrm{M}$ and $\mathrm{E}$ proteins combined with the virion, while S spike protein ensures that the entry receptor on cells is specific for the coronavirus mediators $[3,4]$.

The COVID-19 symptoms are not uniform in all the patients. Asymptomatic or mild symptoms of COVID-19 found in some people could be recovered without hospitalization in $7-14 \mathrm{~d}$, but $\sim 20 \%$ of cases have severe symptoms, which required critical care, morbidity and mortality of COVID-19 are primarily associated with severe acute respiratory distress syndrome (SARDS) due to acute viral pneumonia [5].

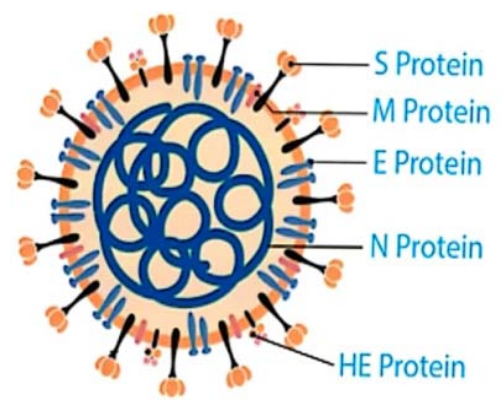

Fig. 1: Basic structure of coronavirus 2 [2]

\section{Transmission and replication of the virus}

The novel coronavirus two can be transmitted between humans via the respiratory tract, close contact is also a transmission source, SARS-CoV-2 can be transmitted through direct or indirect contact with mucous membranes in the eyes, mouth, or nose [6]. Besides, the transmission of SARS-CoV-2 can occur via breast milk or vertically from mother to infant has not been determined COVID-19 patients have some gastrointestinal symptoms, including diarrhea, nausea, and vomiting, a recent study showed that the enteric symptoms of COVID-19 pneumonia are associated with invaded ACE2-expressing enterocytes [7].

Nonetheless, COVID-19 present other clinical highlights that it mainly targets the lower respiratory system with high gastrointestinal side effects; for example, loose belly and chest radiograph show invasion in the upper projection of the left lung, which causes dyspnoea, SARS-CoV-2 contamination includes a twostage safe reaction, the primary period of the reaction is defensive and seen during the hatching time frame in which resistant multiple responses attempts to fight the infection and prevent the infection movement at initial stages, this stage targets the immune cells favorable to harmful macrophages, leucocytes, cytokines and eventually leads to lung injury, which gives a way of multi-organ collapse and finally death in COVID-19 patients [8].

After the infection of SARS-CoV-2, gets replication primarily in the mucosal epithelium of the upper respiratory tract, such as the nasopharynx; fig. 2 shows the replication system of coronavirus when coronavirus attaches to the cell receptors like ACE2 and cell surface factor, the virus would be uptake by the cell endosomal membrane; after that, the RNA would be released and translated immediately into ORF1a and ORF1b (open reading frames). Cotranslational and post-translational modification will occur on polyproteins pp1a and pp1ab into non-structural protein which composes the viral replication and transcription complex. Doublemembrane vesicles, convoluted membranes, tiny open doublemembrane spherules all together provide a protective microenvironment essential in the viral biogenesis and RNA replication transcription; eventually, employing exocytosis, the virion would be released from the cell [9]. 


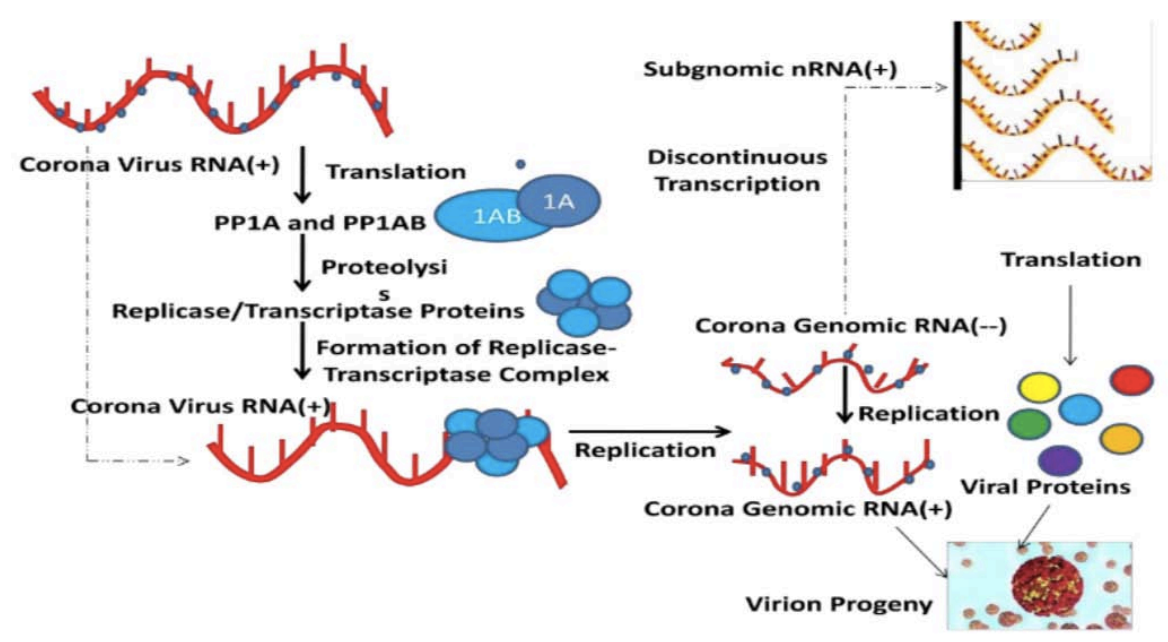

Fig. 2: Shows the replica system of coronavirus [9]

\section{General symptoms of the disease}

The incubation period of SARS-CoV-2 is 6-41 d; this might be different depending on the age, and immunity, and other risk factors; however, in most cases, this period may take $14 \mathrm{~d}$, it was stated that $80 \%$ of the patients had the disease with mild to moderate severity, $13.8 \%$ had a severe illness, and $6.1 \%$ had critically ill (respiratory failure, septic shock and multi-organ dysfunction or failure) [10]. The most observed symptoms are fever, fatigue, and dry cough. Besides these symptoms, headache, nasal congestion, runny or stuffy nose, sore throat, myalgia, and arthralgia may occur. Also, white blood cell counts, lymphopenia, or thrombocytopenia, with the increased C-reactive protein level, maybe observed normal or lower in COVID-19 patients, mild or moderate cases of pneumonia are present or absent; in severe cases, dyspnoea, respiratory frequency $\geq 30 \mathrm{~min}$, blood oxygen saturation $\leq$ $93 \%, \mathrm{PaO} 2 / \mathrm{FiO} 2$ ratio $<300$ or more than $50 \%$ of the lung area of infiltrated areas are observed [11].

\section{Impact of COVID-19 on immunity}

When a person detected with COVID-19, T, and $\beta$ cells would be caught seen in his blood, CD4+T cells play a significant role in initiate the role of both CD8+T cells and $\beta$ cells. When CD8+T cells immediately attack the cells infected with the virus, CD4+T cells will be taking charge of producing new cytokines to boost immune cell induction. Upon examining a patient with COVID-19, his autopsy shows highly accumulated $\mathrm{T}$ cells and monocytes in the lung and reduced $\mathrm{T}$ cells in peripheral blood, this suggests the $\mathrm{T}$ cell drift away from the blood and move towered the infected area to manage the infection [12]. However, after recovery from SARS-CoV infection, patients would have coronavirus-related memory $\mathrm{T}$ cells that would last for two years [13]. Although all findings refer to the vital role of $\mathrm{T}$ cells in fighting the infection, the mice that received the vaccine showed increasing in immunopathology related to TH2 cell instead of prevention from the virus[14].

$\beta$ lymphocyte response to SARS-CoV infection occurs associated with $\mathrm{T}$ lymphocyte response after seven days of the onset of the symptoms, protein, then in week two antibodies response against $S$ protein will occur [15], antibodies will start to neutralize SARS-CoV2 , by week 3 , nearly all patients developing neutralized antibodies. In SARS-CoV-2, both antibody response and viral load appear earlier than SARS-CoV-1. Many patients might not have kept the antibodies of COVID-19, and it is still not clear if they will get the infection again or not. Antibodies usage have previously proved its effectiveness with SARS, convalescent plasma therapy shows a promise result, and in general, the adults with high immunity standards has low mortality rate with the COVID-19 cases [16].

\section{COVID-19 effect on human lungs}

SARS-CoV-2, the disease that causes COVID-19, is a part of the coronavirus family; when the contamination enters in the human body, it comes into contact with the mucous layers of the nose, mouth, and eyes[17]. In the lungs, the infected cell starts damaging the alveoli responsible for the exchange of oxygen and $\mathrm{CO}_{2}$, the severe illness with SARS-CoV-2, when the respiratory system containing the disease enters the upper respiratory part, as the virus contamination increases, the sickness can cause more damages to the lungs due to pneumonia [18].

The first signs of the disease usually appear as dry cough and fever; after about 5-7 d, lung function is impaired, and shortness of breath occurs, furthermore, people who have other chronic diseases such as asthma, heart disease, and chronic lung disease can develop shortness of breath earlier and usually feel greater gasping, after this point, a rapid deterioration in respiratory functions may occur, respiratory injury in $10-20 \%$ of severe patients can become ARDS [19]. This condition can occur within $14 \mathrm{~d}$ of the disease. Therefore, the first treatment approach should be oxygen therapy at the time of hypoxemia (oxygen saturation; SpO2<93\%). However, some patients may develop respiratory failure despite early oxygen therapy. The next step of treatment in these patients is non-invasive ventilation (NIV) or high-flow nasal oxygen therapy (HFNO) [20]. A rapid improvement in partial arterial oxygen pressure $(\mathrm{PaO2}) /$ inspired oxygen fraction (FiO2) is observed with the application of NIV or HFNO treatments [21].

As per the recent survey on the infected COVID-19 patients, most of them suffer from shortness of breath due to the low oxygen exchange rate inside the lungs, the SARS-CoV-2 can damage the alveoli and encompassing tissues and causes pneumonia or Acute Respiratory Distress Syndrome (ARDS) [22].

\section{COVID-19 effect on kidney}

Kidney infection has been reported in a new survey that the patients with different degrees of seriousness of SARS CoV2 contamination, a few reports have watched the event of haematuria and proteinuria in a level of affected patients, those standard hemodialysis might be feeling weak against the virus. As per the existing research on COVID-19, SARS-CoV-2 infection among the poor population establishes a significant test. Great significance has been given to the requirement for ventilators, and all establishments were approached to achieve a lot higher quantities of ventilators facilities at their place [23]. However, it needs to understand that a critical extent of grown-up patients with serious COVID-19 was affected with Acute kidney injury (AKI) with a prerequisite for kidney substitution treatment (KST) [24]. Even though youngsters with COVID-19 illness are less seriously influenced with AKI and the underlying paces of AKI in these children have been discovered to be low, due to the expanded interest for KST in grown-up patients and redirection of KST assets to the grown-up COVID-19 patients, a procedure should be arranged for youngsters in the setting of restricted assets [25]. Moreover, AKI happens with higher 
recurrence in the recently analyzed hyperinflammatory condition in children, which spread a typical Kawasaki disease or harmful stun disorder, Paediatric Inflammatory Multisystem Syndrome: Temporally Associated with SARS-CoV-2 (PIMS-TS) [26]. Cytokine storm, hyper-inflammatory state, hyper-changeability, lack of hydration, and vasculitis are part of the hypothesized clarifications for multisystem inclusion, including AKI, this critique will concentrate on extraordinary transformations (in the setting of hyper-coagulability and expanded channel coagulating) or deviations from the "standard" to be made during the conveyance of KRT to patients with COVID-19 prompted AKI [27]. This is moreover significant for the future with more COVID-19 patients anticipated and pediatricians overseeing either grown-up patients on PICU or being redeployed to the grown-up ICUs to deal with grown-up patients. Critically, if pediatric patients required KST during the pandemic, similar standards will apply as the greater part of the assets (originating from a similar normal pool) would have been occupied to the grown-up patients [28].

\section{COVID-19 effect on cardiovascular system}

Patients who are most vulnerable to the SARS-CoV-2 are old age with chronic diseases such as high blood pressure, diabetes, chronic respiratory diseases, and cardiovascular disease [29]. The theory behind multi-organ damage by the virus is the presence of ACE 2 receptors in the digestive system, heart, Kidney, liver, pancreas, cerebral neurons, vascular endothelial cells, testicles, insusceptible cells, uterus, placenta, and hatchling [30].

COVID-19 is considered a respiratory disease though cardiovascular complications are widespread since clinical studies have shown that cardiovascular disease patients (diabetes, hypertension, myocardial injury) are more vulnerable to new coronavirus disease (COVID-19) and susceptible to experience severe disease [31]. Since cardiovascular disease patients have more ACE2 receptors, they are more vulnerable to vascular endothelial injury. In contrast, COVID patients often have increased angiotensin II in plasma, inflammatory causes, myocardial, body hypoxia, and blood coagulation disorders. Cytokines are proteins that control a wide cluster of biological capacities, one of them being aggravation and fix. The fiery reaction of cytokines can prompt heart harm using the system of cardiovascular breakdown [32].

Myocarditis is an irritation of the heart muscle, It can bring about powerless siphon capacity of the heart muscle, known as a cardiovascular breakdown with decreased discharge division (HFrEF) or systolic cardiovascular breakdown, In the above research report given to ongoing research trusted Source in JAMA Cardiology that finished up heart injury is a typical condition in hospitalized patients with COVID-19 in Wuhan, China. The American College of Cardiology (ACC) recorded the accompanying heart suggestions from coronavirus case reports in late February 2020 [33]. These focus consider since the first case arrived related to heart disorder in American and European case reports like asymptomatic Patients are at higher risk for mortality from COVID-19 [34]. Up to $50 \%$ of hospitalized patients have an interminable clinical sickness [35]. The $40 \%$ of COVID-19 patients have a cardiovascular or cerebrovascular disorder,16.7 \% of patients affected with arrhythmia, $7.2 \%$ infected with intense cardiovascular injury, $8.7 \%$ t of patients infected with a stun, and 3.6\% caused AKI [36].

\section{COVID-19 effect on diabetes patients}

4.63 billion patients around the world have type2 diabetes, with 1 million deaths till 2017[37]. This chronic severe disease was found to worsen and most affected by the coronavirus; Chinese Centre for Disease Control (CDC) reported that the death rate percentage increased with coronavirus patients with diabetes to $7.3 \%$ while alone without diabetes was only 2.3\% [38]. Italy's percent was 35.5 died from diabetes and the virus infection[39]. American Centres for Disease Control and Prevention stated last March, that the most infected coronavirus patients were had diabetes and $32 \%$ required in hospitalization intensive care unit [40]. Regarding the diabetes wound, $15.4 \%$ of 39 patients stated that their wound got deteriorated during the pandemic through an antibiotic was added to their therapy protocol, $35.9 \%$ were changing their wound dress at home, $12.8 \%$ were not take off the dressing [41].
While SARS-CoV-2 binds to ACE2 and enters the human lung, it has been found that ACE2 expression is increased in the lung of diabetic type2 patients [42]. Another study state that severe lung injury could happen when ACE2 level decrease in the lung [43]. Another reason that might increase the infection possibilities of COVID-19 in diabetic patients is Furin, ' 'which's found to be increased in diabetic patients, which would facilitate the penetration of SARS-CoV-2 in the cell because Furin is a member of the proprotein convertase subtilisin/kexin family, that also could facilitate the SARS-CoV-2 replication [44]. Also, there is a link between Interleukin- 6 and SARS-CoV-2; diabetes patients infected with COVID-19 showed a high level of Interleukin-6 [45]. Moreover, lymphocytopenia has been noticed in COVID-19 patients and linked with T-Cell deterioration [46]. After all, several factors might affect the mortality of coronavirus patients, such as age, period of infection, gender, and blood glucose level [47]. However, more studies needed to be done to see the effects of diabetes on COVID-19 mortality.

\section{COVID-19 impact on children and newly born babies}

In this pandemic, the low number of cases in children while it was more significant in adults, the rate of children infection with COVID19 has expanded significantly, as of the way that children couldn't wear protective kits and couldn't take other preventive measures which are essential during this pandemic. Yet, there is insufficient proof on the methodology towards pediatric patients and infants, the impact of COVID-19 on the embryo, and the wellbeing of breastfeeding and clinical investigations areas still in progress [48]. In general, COVID infections in children are mild symptoms and, in most cases, don't require in-hospital treatment; it has been reported that SARS-CoV-2 in children affected less than $5 \%$ of the total infected people around the world, their symptoms were mild, most of them experience mild respiratory symptoms like cough and fever, deficient percentage $4 \%$ recorded severe symptoms [49]. The mortality rate in children is infrequent with coronavirus; out of 578 patients, only four have died, which is less than $0.69 \%$ [50]. It is found in one investigation the total of 72,314 cases determined to have positive COVID-19, $1 \%$ or less patient with severe sickness died $(2.3 \%)$ among $43.707 \%$ patients older than $20 \mathrm{y}$ of age. Just a single failure among 549 patients matured $10-19$ y $(\% 0.2)$, and no loss among 416 patients between the ages of $0-9(0 \%)$ was reported [51]. Information distributed in Italy on March 18, 2020, announced that $1.2 \%$ of 22,512 COVID-19 Italian cases were youngsters, and there was no downfall in children 5\% of 4,226 COVID-19 cases analyzed in the USA until March 16 [52]. It has been reported that children with less than $5 \%$ in China with a serious infection and required in-hospital stay [53]. In contrast, Children represented under $1 \%$ of all COVID-19 hospitalizations in the USA [54]. This disease is influencing patients from all age groups in the Chinese pediatric case arrangement (with 2143 cases), while 171 children are detailed from the Wuhan pediatric medical clinic under $7 \mathrm{y}$ of age [55]. Nine pregnant women reported with COVID-19 and transfer the infection for their infants due to the direct contact through the labour process [56]. Another study stated that Turkey announced that just $1 \%$ of 11535 COVID-19 cases were children by the end of March [57]. Recent studies say that there are no gender differences in COVID-19 infection between female and male children. Although infants are more susceptible to having the virus than young children; adults remain the most affected [58].

Due to the insufficient information regarding the matter, the radiographic highlights of babies with lower respiratory diseases identified with SARS-CoV-2 are not enough to be distinguished. According to further investigations, discoveries of pneumonia were characterized on chest radiography of 3 infants determined to have early neonatal COVID-19 [59]. The affectability of chest radiography is low in youngsters; in the beginning phases, chest radiography might be ordinary and don't show ground-glass injuries, yet in extreme cases, advance to respective multifocal union might be watched [60].

\section{Developments on covid-19 treatments}

A recent study is designed to describe Chinese herbal medicine (CHM) therapy, outcomes, and safety with patients experiencing symptoms possibly related to COVID-19; twenty-two participants 
have enrolled to date, of which 14 (63\%) were female and 8 (36\%) male. The median age is 51 (range 22-65). Sixty-one consultations were administered [median 3 (range 1-8)] per participant. In the acute phase of illness, the primary symptom reported was fever and chills $(54 \%)$, fatigue $(45 \%)$, and sore throat $(23 \%)$. No adverse events occurred related to the intervention [61]. Describing individualized CHM treatment as a potential COVID-19 therapy will provide vital preliminary data on the methods, feasibility, acceptability, tolerability, effectiveness, and safety. The important findings from the study will inform future controlled trials of individualized CHM therapy for symptoms related to COVID-19 [62]. The treatment is fundamentally organized by utilizing clinical involvement in grown-up patients. COVID-19 doesn't have a particular medical treatment in adolescence [63]. Indicative and intense treatment, oxygen treatment and liquid electrolyte uphold are recommended. For infants, high-portion pneumonic surfactant breathed in nitric oxide, HFO (high-frequency oscillations) treatment and ECMO (extracorporeal membrane oxygenation) can be valuable [64]. Oxygen treatment and mechanical ventilator uphold must be given to patients with respiratory misery and SARS with oxygen treatment immersion at a level above 94\% [64]. Antiviral can be considered with regards to clinical investigations on a case premise. All antiviral use ought to be considered tentatively because of the nonattendance of antiviral that has demonstrated viability for treatment and ought to be tried in clinical preliminaries to guarantee adequacy and wellbeing [65]

Hydroxychloroquine and chloroquine, which repress SARS CoV-2 in vitro (hinder access to cells) are FDA affirmed and broadly utilized for the treatment and prophylaxis of intestinal sickness [66]. Hydroxychloroquine is additionally FDA affirmed for discoid lupus erythematosus, foundational lupus erythematosus and rheumatoid joint pain [67]. There is not satisfactory proof of its utilization in the treatment of pediatric COVID-19; however, it has pediatric clinical experience attributable to its worthy symptom profile and different signs [68]. The treatment of azithromycin is not suggested because it increments heart reactions [69]. Baby and youngster dose is 13 $\mathrm{mg} / \mathrm{kg} /$ portion (most extreme: $800 \mathrm{mg} /$ portion) followed by 6.5 $\mathrm{mg} / \mathrm{kg} /$ portion (greatest: $400 \mathrm{mg} /$ portion) to be taken 6,24 and 48 $\mathrm{h}$ after the underlying portion [70]. Given that intense jungle fever has a 3-day therapy period, it is prescribed not to be given longer than $5 \mathrm{~d}$ in COVID-19 with regards to clinical preliminaries [71].

Remdesivir is a simple nucleotide prodrug that restrains viral RNA polymerase, it has been discovered to be compelled in SARS CoV-2 in vitro investigations [72]. It is suggested utilizing remdesivir as a feature of the clinical preliminary [73].

Favipiravir (FPV) is another medication that is right now going through clinical exploration for the treatment of COVID-19, yet there is not any proof for pediatric patients with serious COVID-19 [74] This medication is an RNA-subordinate RNA polymerase inhibitor, and it has been discovered successful in Ebola treatment [75]

The treatment of Lopinavir/Ritonavir (LPV/RTV), which is a protease inhibitor utilized in HIV disease, has a shallow job in the treatment of SARS-CoV-2 contamination, and it has been seen in past examinations that it has some action against SARS CoV and MERSCoV [76]. The utilization of LPV/RTV, which is the main tablet structure that can be utilized securely in HIV-tainted pregnant ladies, is available to discuss infants and youngsters [77]. Antiviral medications suggested in SARS-CoV-2 contamination can be considered in treating infants and youngsters after the hazard advantage proportion is deliberately assessed in a setting of clinical preliminaries [78]. The issue of iatrogenic concealment of resistance because of cytokine storm in COVID-19 has been arranged; it is not prescribed to give corticosteroids, particularly in the present restricted logical proof due to the lower safe reaction in youngsters followed with adults $[78,79]$. If there is proof of auxiliary bacterial disease, the important anti-infection agents should be utilized [80]. In Children, a treatment that has an expanded danger of apoplexy and can be treated with low sub-atomic weight heparin in beginning phases and anticoagulant therapy can be controlled if vital [78] Healing plasma treatment can be utilized in youngsters whose clinical condition disintegrates quickly, genuine and basic illnesses [81].

Table 3: Shows the treatment dosage and clinical trial stage

\begin{tabular}{|c|c|c|c|}
\hline Treatments & Dosage & Clinical stage & References \\
\hline Hydroxychloroquine & $400 \mathrm{mg}$ & Initial & {$[82,83]$} \\
\hline Remdesivir & $200 \mathrm{mg}$ & Initial & {$[84,85]$} \\
\hline Favipiravir & $200 \mathrm{mg}$ & Phase 2 & {$[86,87]$} \\
\hline Lopinavir/Ritonavir & $\begin{array}{l}\text { LPV-800 mg } \\
\text { RTV-200 mg }\end{array}$ & Initial & {$[88,89]$} \\
\hline
\end{tabular}

\section{CONCLUSION}

We are assuming that the contact of ACE 2 and its upregulation in various neurotic conditions making patients more helpless to SARSCoV-2 contamination and can add to an expansion in mortality. COVID-19 is a worldwide concern. Its pathophysiology is exceptionally intricating, which involves researching the utilization of first-line drugs in the treatments of toxaemia, cardiovascular illnesses, Pneumonia, and Acute kidney injury diabetes, and its difficulties, asthma, NASH, safe related sicknesses, and malignant growth. Thus, there is an essential requirement for care to those patients who have SARS-CoV-2 contamination fundamental with various ailments. It may expand the seriousness and mortality in comorbid conditions due to multi-organ damage due to contamination with infection and cytokine storm. Hence focusing on the cooperation of SARS-CoV-2 to ACE 2 could be the future novel therapeutic way to deal with reduce the multiple organ transmission and damage. Clinical experience of children and babies with COVID19 is a step-by-step expansion, and the methodologies suggested here depend on accessible proof. Although continuous research in pediatric patients contrasted with grown-up patients in the COVID19 pandemic, it is necessary to consider during the treatment choice that children infected with heart and respiratory illness may advance highly dependent on clinical experience from other viral contaminations. Concerns stay due to COVID-19 mother-child vertical transmission and absence of proof on possible fatal results further investigations are required.

\section{ACKNOWLEDGMENT}

There is no acknowledgment for this work.

\section{FUNDING}

Nil

\section{AUTHORS CONTRIBUTIONS}

Author 1: Wrote the article, Author 2: Revising and do corrections, Author 3: Grammar corrections, Authors 4: Data collections, Authors 5: Article designing, Authors 6: Data collection, Author 7: Paper writing contribution

\section{CONFLICT OF INTERESTS}

There is no conflict of interest for this work.

\section{REFERENCES}

1. Lian J, Jin X, Hao S, Jia H, Cai H, Zhang X, et al. Epidemiological, clinical, and virological characteristics of 465 hospitalized cases of coronavirus disease 2019 (COVID-19) from Zhejiang province in China. Influenza Other Respiratory Viruses 2020;14:564-74.

2. Hoffmann M, Kleine Weber H, Schroeder S, Kruger N, Herrler T, Erichsen S, et al. SARS-CoV-2 cell entry depends on ACE2 and TMPRSS2 and is blocked by a clinically proven protease inhibitor. Cell 2020;181:271-80. e8. 
3. Klein S, Cortese M, Winter SL, Wachsmuth Melm M, Neufeldt CJ, Cerikan B, et al. SARS-CoV-2 structure and replication characterized by in situ cryo-electron tomography. Nature Communications 2020;11:1-10.

4. Navdeep K, Simranpreet K, Manjinder K. A review on the fifth pandemic: coronavirus. Asian J Pharm Clin Res 2020;13:25-31.

5. Grasselli G, Pesenti A, Cecconi M. Critical care utilization for the COVID-19 outbreak in Lombardy, Italy: early experience and forecast during an emergency response. JAMA 2020;323:1545-6.

6. Neela B, Jakkula S, Gaur RP. Corticosteroids and secondary infections: an insight into coronavirus disease-2019. Asian J Pharm Clin Res 2021;14:36-47.

7. Wang $\mathrm{D}, \mathrm{Hu} \mathrm{B}, \mathrm{Hu} \mathrm{C}$, Zhu F, Liu X, Zhang J, et al. Clinical characteristics of 138 hospitalized patients with 2019 novel coronavirus-infected pneumonia in Wuhan, China. JAMA 2020;323:1061-9.

8. Dariya B, Nagaraju GP. Understanding novel COVID-19: its impact on organ failure and risk assessment for diabetic and cancer patients. Cytokine Growth Factor Rev 2020;53:43-52.

9. V'kovski P, Kratzel A, Steiner S, Stalder H, Thiel V. Coronavirus biology and replication: implications for SARS-CoV-2. Nat Rev Microbiol 2021:19:155-70.

10. Lessler J, Reich NG, Brookmeyer R, Perl TM, Nelson KE, Cumming DA. Incubation periods of acute respiratory viral infections: a systematic review. Lancet Infect Dis 2009;9:291-300.

11. Chen G, Wu D, Guo W, Cao Y, Huang D, Wang H, et al. Clinical and immunologic features in severe and moderate forms of coronavirus disease 2019. J Clin Invest 2020;130:2620-9.

12. Zheng HY, Zhang M, Yang CX, Zhang N, Wang XC, Yang XP, et al. Elevated exhaustion levels and reduced functional diversity of $\mathrm{T}$ cells in peripheral blood may predict severe progression in COVID-19 patients. Cell Mol Immunol 2020;17:541-3.

13. Libraty DH, O'Neil KM, Baker LM, Acosta LP, Olveda RM. Human CD4+memory T-lymphocyte responses to SARS coronavirus infection. Virology 2007;368:317-21.

14. Bolles M, Deming D, Long K, Agnihothram S, Whitmore A, Ferris $\mathrm{M}$, et al. A double-inactivated severe acute respiratory syndrome coronavirus vaccine provides incomplete protection in mice and induces increased eosinophilic proinflammatory pulmonary response upon challenge. J Virol 2011;85:12201-15

15. Thevarajan I, Nguyen TH, Koutsakos M, Druce J, Caly L, Van de Sandt CE, et al. Breadth of concomitant immune responses prior to patient recovery: a case report of non-severe COVID19. Nat Med 2020;26:453-5.

16. Salazar E, Christensen PA, Graviss EA, Nguyen DT, Castillo B, Chen J, et al. Treatment of coronavirus disease 2019 patients with convalescent plasma reveals a signal of significantly decreased mortality. Am J Pathol 2020;190:2290-303.

17. Joseph SK, MA A, Thomas S, Nair SC. State-of-the-art nanotechnology-based drug delivery strategies to combat covid-19. Int J Appl Pharm 2021;13:18-29.

18. Hafiane A. SARS-CoV-2 and the cardiovascular system. Clin Chim Acta 2020;510:311-6.

19. Duramad P, Tager IB, Holland NT. Cytokines and other immunological biomarkers in children's environmental health studies. Toxicol Lett 2007;172:48-59.

20. Lyons $\mathrm{C}$, Callaghan $\mathrm{M}$. The use of hifgew nasal oxygen in COVID-19. Anaesthesia 2020;75:843-7.

21. Ferrando C, Mellado Artigas R, Gea A, Arruti E, Aldecoa C, Adalia $\mathrm{R}$, et al. Awake prone positioning does not reduce the risk of intubation in COVID-19 treated with high-flow nasal oxygen therapy: a multicenter, adjusted cohort study. Critical Care 2020;24:1-11

22. Lauer SA, Grantz KH, Bi Q, Jones FK, Zheng Q, Meredith HR, et al. The incubation period of coronavirus disease 2019 (COVID19) from publicly reported confirmed cases: estimation and application. Annals Int Med 2020;172:577-82.

23. Alberici F, Delbarba E, Manenti C, Econimo L, Valerio F, Pola A, et al. A single-center observational study of the clinical characteristics and short-term outcome of 20 kidney transplant patients admitted for SARS-CoV2 pneumonia. Kidney Int 2020;97:1083-8.

24. Hultstöm M, Von Seth M, Frithiof R. Hyperreninemia and low total body water may contribute to acute kidney injury in coronavirus disease 2019 patients in intensive care. J Hypertension 2020. DOI:10.1097/HJH.0000000000002531
25. Rahimi H, Tehranchinia Z. A comprehensive review of cutaneous manifestations associated with COVID-19. BioMed Res Int 2020;2020:1236520.

26. Davies P, Evans C, Kanthimathinathan HK, Lillie J, Brierley J, Waters G, et al. Intensive care admissions of children with paediatric inflammatory multisystem syndrome temporally associated with SARS-CoV-2 (PIMS-TS) in the UK: a multicentre observational study. Lancet Child Adolescent Health 2020;4:669-77.

27. Parikh CR, Han G. Variation in performance of kidney injury biomarkers due to cause of acute kidney injury. Am J Kidney Diseases 2013;62:1023-6.

28. Wang L, Li X, Chen H, Yan S, Li D, Li Y, et al. Coronavirus disease 19 infection does not result in acute kidney injury: an analysis of 116 hospitalized patients from Wuhan, China. Am J Nephrol 2020;51:343-8.

29. Alberca RW, Aoki V, Sato MN. COVID-19 and HIV: case reports of 2 co-infected patients with different disease courses. World Academy Sci J 2021;3:1-4.

30. Navik U, Bhatti J, Sheth V, Jawalekar S, Bhatti G, Kalra S. Multiorgan failure in COVID-19 patients: a possible mechanistic approach. Authorea Preprints 2020 DOI:10.22541/au.159110399.94076751

31. Mehra MR, Desai SS, Kuy SR, Henry TD, Patel AN. Retraction: cardiovascular disease, drug therapy, and mortality in covid19. New England J Med 2020;382:2582.

32. Clerkin KJ, Fried JA, Raikhelkar J, Sayer G, Griffin JM, Masoumi A, et al. COVID-19 and cardiovascular disease. Circulation 2020;141:1648-55.

33. Guo $Q$, Feng $X$, Zhou Y. Potential impact of brain and heart interaction on cardiovascular system in covid-19 patients. Authorea Preprints 2020. DOI:10.22541/au.159373155.50189648

34. Hangargekar CB, Quazi RS, Joshi AA. A review on covid-19-a global battle between life and death. Int J Curr Pharm Res 2020;12:19-24.

35. Matsushita K, Marchandot B, Jesel L, Ohlmann P, Morel 0 . Impact of COVID-19 on the cardiovascular system: a review. J Clin Med 2020;9:1407.

36. Yoganathan A, Sajjad M, Harky A. Cardiovascular disease and the impact of COVID-19. Authorea Preprints 2020;35:2113.

37. Global, regional, and national age-sex-specific mortality for 282 causes of death in 195 countries and territories, 1980-2017:a systematic analysis for the global burden of disease study 2017. Lancet 2018;392:1736-88.

38. Wu Z, McGoogan JM. Characteristics of and important lessons from the coronavirus disease 2019 (COVID-19) outbreak in China: summary of a report of 72314 cases from the Chinese center for disease control and prevention. JAMA 2020;323:1239-42.

39. Fadini G, Morieri M, Longato E, Avogaro A. Prevalence and impact of diabetes among people infected with SARS-CoV-2. J Endocrinol Invest 2020;43:867-9.

40. Preliminary estimates of the prevalence of selected underlying health conditions among patients with coronavirus disease 2019united states. MMWR Morb Mortal Wkly Rep 2020;69:382-6.

41. Tinelli G, Sica S, Guarnera G, Pitocco D, Tshomba Y. Wound care during COVID-19 pandemic. Annals Vascular Surgery 2020;68:93-4.

42. Rao S, Lau A, So HC. Exploring diseases/traits and blood proteins causally related to the expression of ACE2, the putative receptor of SARS-CoV-2: A mendelian randomization analysis highlights tentative relevance of diabetes-related traits. Diabetes Care 2020;43:1416-26.

43. AlGhatrif M, Cingolani O, Lakatta EG. The dilemma of coronavirus disease 2019, aging, and cardiovascular disease: insights from cardiovascular aging science. JAMA Cardiol 2020;5:747-8

44. Fernandez C, Rysa J, Almgren P, Nilsson J, Engstrom G, Orho Melander $\mathrm{M}$, et al. Plasma levels of the proprotein convertase furin and incidence of diabetes and mortality. J Int Med 2018;284:377-87.

45. Maddaloni E, Buzzetti R. Cevod and diabetes mellitu s: unveiling the interaction of two pandemics. Diabetes/Metab Res Rev 2020;31:e33213321. 
46. Kulcsar KA, Coleman CM, Beck SE, Frieman MB. Comorbid diabetes results in immune dysregulation and enhanced disease severity following MERS-CoV infection. JCI Insight 2019;4:e131774.

47. Yang Y, Zhong W, Tian Y, Xie C, Fu X, Zhou H. The effect of diabetes on mortality of COVID-19: a protocol for systematic review and meta-analysis. Medicine (Baltimore) 2020;99:e20913.

48. Lu X, Zhang L, Du H, Zhang J, Li YY, Qu J, et al. SARS-CoV-2 infection in children. New England J Med 2020;382:1663-5.

49. Meena J, Yadav J, Saini L, Yadav A, Kumar J. Clinical features and outcome of SARS-CoV-2 infection in children: a systematic review and meta-analysis. Indian Pediatrics 2020;57:820-6.

50. Gotzinger F, Santiago Garcia B, Noguera Julian A, Lanaspa M Lancella L, Carducci FIC, et al. COVID-19 in children and adolescents in Europe: a multinational, multicentre cohort study. Lancet Child Adolescent Health 2020;4:653-61.

51. Novel CPERE. The epidemiological characteristics of an outbreak of 2019 novel coronavirus diseases (COVID-19) in China. Zhonghua Liuxingbingxue Zazhi 2020;41:145-51.

52. Ludvigsson JF. Systematic review of COVQD in children shows milder cases and a better prognosis than adults. Acta Paediatrica 2020;109:1088-95.

53. Dong Y, Mo X, Hu Y, Qi X, Jiang F, Jiang Z, et al. Epidemiology of COVID-19 among children in China. Pediatrics 2020;145. https://doi.org/10.1542/peds.2020-0702

54. Holshue ML, DeBolt C, Lindquist S, Lofy KH, Wiesman J, Bruce $\mathrm{H}$, et al. First case of 2019 novel coronavirus in the United States. New England J Med; 2020.

55. Dong Y, Mo X, Hu Y, Qi X, Jiang F, Jiang Z, et al. Epidemiological characteristics of 2143 pediatric patients with 2019 coronavirus disease in China. Pediatrics 2020. DOI:10.1542/peds.2020-0702

56. Luo Y, Yin K. Management of pregnant women infected with COVID-19. Lancet Infectious Diseases 2020;20:513-4.

57. Hayakawa K, Mukunoki H. Impacts of covid-19 on international trade: evidence from the first quarter of 2020. Institute of Developing Economies, Japan External Trade Organization (JETRO); 2020.

58. Navidinia M, Goudarzi $M$. The main associated symptoms related to covid-19 (Coronavirus disease 2019) among pediatric patients. Arch Adv Biosci 2020;11:64-72.

59. Zhu N, Zhang D, Wang W, Li X, Yang B, Song J, et al. A novel coronavirus from patients with pneumonia in China, 2019. New England J Med 2020;382:727-33.

60. Bayramoglu Z, Canıpek E, Comert RG, Gasimli N, Kaba O, Yanartas MS, et al. Imaging features of pediatric covid-19 on chest radiography and chest CT: A retrospective, single-center study. Academic Radiol 2020;28:18-27.

61. Cheng Y, Wong R, Soo Y, Wong W, Lee C, Ng M, et al. Use of convalescent plasma therapy in SARS patients in Hong Kong. Eur J Clin Microbiol Inf Diseases 2005;24:44-6.

62. Koyama T, Weeraratne D, Snowdon JL, Parida L. Emergence of drift variants that may affect COVID-19 vaccine development and antibody treatment. Pathogens 2020;9:324.

63. Klok F, Kruip M, Van der Meer N, Arbous M, Gommers D, Kant $\mathrm{K}$, et al. Incidence of thrombotic complications in critically ill ICU patients with covid-19. Thrombosis Res 2020;191:145-7.

64. Bhattacharyya $\mathrm{R}$, Iyer $\mathrm{P}$, Phua GC, Lee JH. The interplay between coagulation and inflammation pathways in COVID-19associated respiratory failure: a narrative review. Pulm Ther 2020;6:215-31.

65. Gombart AF. The vitamin D-antimicrobial peptide pathway and its role in protection against infection. Future Microbio 2009;4:1151-65.

66. Pillat MM, Kruger A, Guimaraes LMF, Lameu C, de Souza EE, Wrenger $\mathrm{C}$, et al. Insights in chloroquine action: perspectives and implications in Malaria and covid-19. Cytometry Part A 2020;97:872-81.

67. Chen Y, Chen L, Deng Q, Zhang G, Wu K, Ni L, et al. The presence of SARS-CoV-2 RNA in the feces of COVID-19 patients. J Med Virol 2020;92:833-40

68. Campbell JI, Ocwieja KE, Nakamura MM. A call for pediatric covid-19 clinical trials. Pediatrics 2020;146. https://doi.org/ 10.1542/peds.2020-1081.
69. Group SC-G. Genomewide association study of severe Covid-19 with respiratory failure. New England J Med 2020;383:1522-34.

70. Luo Y, Trevathan E, Qian Z, Li Y, Li J, Xiao W, et al. Asymptomatic SARS-CoV-2 infection in household contacts of a healthcare provider, Wuhan, China. Emerging Infect Dis 2020;26:1930.

71. Yan Y, Zou Z, Sun Y, Li X, Xu KF, Wei Y, et al. Anti-malaria drug chloroquine is highly effective in treating avian influenza A H5N1 virus infection in an animal model. Cell Res 2013;23:300-2.

72. Sheahan TP, Sims AC, Leist SR, Schafer A, Won J, Brown AJ, et al Comparative therapeutic efficacy of remdesivir and combination lopinavir, ritonavir, and interferon-beta against MERS-CoV. Nat Commun 2020;11:1-14.

73. Wang Y, Zhang D, Du G, Du R, Zhao J, Jin Y, et al. Remdesivir in adults with severe COVID-19: a randomised, double-blind, placebo-controlled, multicentre trial. Lancet 2020 https://doi.org/10.1016/S0140-6736(20)31022-9

74. Cai Q, Yang M, Liu D, Chen J, Shu D, Xia J, et al. Experimental treatment with favipiravir for COVID-19: an open-label control study. Engineering 2020;6:1192-8.

75. Wang Z, Chen X, Lu Y, Chen F, Zhang W. Clinical characteristics and therapeutic procedure for four cases with 2019 novel coronavirus pneumonia receiving combined Chinese and Western medicine treatment. Bioscience Trends 2020;14:64-8.

76. Arabi YM, Hajeer AH, Luke T, Raviprakash K, Balkhy H, Johani S, et al. Feasibility of using convalescent plasma immunotherapy for MERS-CoV infection, Saudi Arabia. Emerging Infect Dis 2016;22:1554.

77. Amirian ES. Potential fecal transmission of SARS-CoV-2: current evidence and implications for public health. Int J Inf Diseases 2020;95:363-70.

78. Lin S, Shen R, Guo X. Molecular modeling evaluation of the binding abilities of ritonavir and lopinavir to Wuhan pneumonia coronavirus proteases. bioRxiv 2020 https://doi.org/10.1101/2020.01.31.929695

79. Walmsley S, Bernstein B, King M, Arribas J, Beall G, Ruane P, et al. Lopinavir-ritonavir versus nelfinavir for the initial treatment of HIV infection. New England J Med 2002;346:2039-46.

80. Pulido F, Arribas JR, Delgado R, Cabrero E, Gonzalez Garcia J, Perez Elias MJ, et al. Lopinavir-ritonavir monotherapy versus lopinavir-ritonavir and two nucleosides for maintenance therapy of HIV. AIDS 2008;22:F1-F9.

81. Chu C, Cheng V, Hung I, Wong M, Chan K, Chan K, et al. Role of lopinavir/ritonavir in the treatment of SARS: initial virological and clinical findings. Thorax 2004;59:252-6.

82. Zhang J, Zhou L, Yang Y, Peng W, Wang W, Chen X. Therapeutic and triage strategies for 2019 novel coronavirus disease in fever clinics. Lancet Res Med 2020;8:e11-e2.

83. Torjesen I. Covid-19: hydroxychloroquine does not benefit hospitalised patients, UK trial finds. Br Med J 2020;369. https://doi.org/10.1136/bmj.m2650

84. Davis MR, McCreary EK, Pogue JM. That escalated quickly: remdesivir's place in therapy for covid-19. J Infect Dis Ther 2020;9:525-36

85. Paladugu S, Donato AA. Remdesivir improved time to recovery in adults hospitalized with covid-19 and lower respiratory tract involvement. Ann Intern Med 2020;173:JC4.

86. Bouazza N, Treluyer JM, Foissac F, Mentre F, Taburet AM, Guedj $\mathrm{J}$, et al. Favipiravir for children with Ebola. Lancet 2015;385:603-4

87. Jones B, Ma E, Peiris J, Wong P, Ho J, Lam B, et al. Prolonged disturbances of in vitro cytokine production in patients with severe acute respiratory syndrome (SARS) treated with ribavirin and steroids. Clin Exp Immunol 2004;135:467-73.

88. Griffin S. Covid-19: lopinavir-ritonavir does not benefit hospitalised patients, UK trial finds. Br Med J Publishing Group 2020;370:m2650.

89. Yao TT, Qian JD, Zhu WY, Wang Y, Wang GQ. A systematic review of lopinavir therapy for SARS coronavirus and MERS coronavirus-a possible reference for coronavirus diseas $\Theta$ treatment option. J Med Virol 2020;92:556-63. 